\title{
Problems with preference and place of death for children too
}

\author{
Myra Bluebond-Langner professor and True Colours chair in palliative care for children and young \\ people ${ }^{1}$, Emma Beecham research associate ${ }^{2}$, Bridget Candy senior research associate ${ }^{2}$, Richard \\ Langner honorary senior research associate ${ }^{1}$, Louise Jones senior clinical lecturer ${ }^{2}$
}

${ }^{1}$ Louis Dundas Centre for Children's Palliative Care, UCL-Institute of Child Health, London WC1N 1EH, UK; ${ }^{2}$ Marie Curie Palliative Care Research Unit, UCL Mental Health Sciences Unit, University College Medical School, London, UK

The problems raised by Pollock about preference and place of death also apply to seriously ill children, even though choices about care are made with or by a person other than the patient and children typically have one or more devoted carer. ${ }^{1}$ Our systematic review of empirical research on preference for place of death for seriously ill children found, as Pollock does for adults, a lack of evidence for the oft repeated claim that most parents and children would prefer home as the place of death. ${ }^{2}$ Other problems are that preferences change over the course of illness, some people delay or do not wish to express a preference, and some children die without a conscious choice of location having been made.

The proportion of seriously ill children who die at home or who attain a preference for place of death is not a useful outcome measure; neither reliably reflects the success of a team or of a system to provide quality healthcare or a good death. Perhaps what is most important for seriously ill children and their families is to have some discussion about priorities and options for current and future care, rather than to have made a particular choice ${ }^{3}$ - one that is not easily taken in the face of often uncertain and changing circumstances.

Competing interests: None declared.

Pollock K. Is home always the best and preferred place of death? BMJ 2015;351:h4855 (7 October.)

2 Bluebond-Langner M, Beecham E, Candy B, et al. Preferred place of death for children and young people with life-limiting and life-threatening conditions: a systematic review of the literature and recommendations for future inquiry and policy. Palliat Med 2013;27:705-13.

3 Dussel V, Kreicbergs $\mathrm{U}$, Hilden JM, et al. Looking beyond where children die: determinants and effects of planning a child's location of death. J Pain Symptom Manage 2009;37:33-43.

Cite this as: BMJ 2015;351:h6123

๑ BMJ Publishing Group Ltd 2015 